\title{
A BNCC E A História ANTIGa: UMA POSSÍVEL COMPREENSÃO DO PRESENTE PELO PASSADO E DO PASSADO PELO PRESENTE
}

\author{
Ana Lucia Santos Coelho \\ Ygor Klain Belchior ${ }^{2}$
}

Resumo: O objetivo deste artigo é apresentar de que modo as pesquisas em História Antiga foram e podem ser associadas à contemporaneidade política brasileira. Para tanto, mostraremos a princípio um breve panorama sobre o desenvolvimento da Base Nacional Comum Curricular e a exclusão da História Antiga do projeto inicial. Em seguida, apontaremos as críticas acerca de tal eliminação e a importância da disciplina para a compreensão do presente. Por fim, demonstraremos como podemos relacionar o Principado de Nero com o afastamento da Presidenta Dilma Lana Rouseff. O referencial teórico empregado nesse artigo pautou-se no conceito de Anacronismo e na concepção de tempo não-linear, discutida por Bevernage e Lorenz (2013).

PALAVRAS-CHAVE: BNCC; História Antiga; Principado de Nero.

ABSTRACT: The aim of this paper is to demonstrate how the research on ancient history have been and may be associated with modern Brazilian politics. Therefore, we will start from a brief overview of the development of the "Base Nacional Comum Curricular" and the exclusion of the subject Ancient History in its initial project. Then we will point out the criticism about such elimination and the importance of this area for understanding of the present times. Finally, we will demonstrate how we can relate Nero Principate with the impeachment of the President Dilma Rousseff Lana. The theoretical framework used in this paper was guided by the concept of Anachronism and the concept of non-linear time, discussed by Bevernage and Lorenz (2013).

KEYWORDS: BNCC; Ancient History; Neronian Principate.

\footnotetext{
${ }^{1}$ Doutoranda em História pela Universidade Federal de Ouro Preto (UFOP), sob orientação do Professor Dr. Fábio Faversani. É membro do Laboratório de Estudos sobre o Império Romano (LEIR/UFOP). E-mail: ana.scoelho@hotmail.com.

2 Doutorando em História Social pela Universidade de São Paulo, sob a orientação do Professor Dr. Norberto Luiz Guarinello. É membro do Laboratório de Estudos sobre o Império Romano e Mediterrâneo Antigo (LEIR-MA/USP) e Professor de História Antiga da Universidade Federal de Ouro Preto (UFOP).E-mail: ykbelchi@usp.br.
} 


\section{Introdução: o surgimento da Base Nacional Comum Curricular}

A necessidade da implantação de um currículo nacional já é discutida no Brasil há muito tempo. Sua criação está sugerida na Constituição Federal de 1988 que determina como dever do Estado a fixação de "[...] conteúdos mínimos para o ensino fundamental, de maneira a assegurar formação básica comum e respeito aos valores culturais e artísticos, nacionais e regionais" (Brasil, 1988, Art. 210).

A ideia da criação desse currículo, contudo, nunca foi bem aceita pelas universidades. Os docentes argumentavam que a imposição de conteúdos e objetivos comuns a todas as escolas do país "[...] funcionaria como uma camisa de força, eliminando a liberdade de ensino. Daí, então, estados e municípios criaram (ou não) seu próprio currículo, e os colégios particulares adotaram os seus, mirando os vestibulares e o Enem" (Domingues, 2015).

Para o desenvolvimento de tal currículo "específico", as instituições não tiveram sequer um direcionamento legal. A Lei de Diretrizes e Bases (LDB) de 1996, por exemplo, não estabeleceu quais conhecimentos deveriam ser abordados em sala de aula. O documento discutiu apenas os princípios e fins da educação nacional; o direito à educação e o dever de educar; e as disposições e objetivos dos ensinos infantil, fundamental, médio, especial, profissional e superior (Brasil, 1996).

Os Parâmetros Curriculares Nacionais (PCNs) de 1997-1998 também não expressaram com clareza o que exatamente os alunos deveriam aprender. $\mathrm{O}$ material até apresenta um tópico intitulado Conteúdos, porém, não delimita quais conteúdos deverão ser estudados e sim como:

[...] Ao invés de um ensino em que o conteúdo seja visto como fim em si mesmo, o que se propõe é um ensino em que o conteúdo seja visto como meio para que os alunos desenvolvam as capacidades que lhes permitam produzir e usufruir dos bens culturais, sociais e econômicos (Brasil, 1997-1998, p. 51).

Foi o Plano Nacional de Educação (PNE), transformado em lei no ano de 2014, que tornou urgente a criação de um currículo nacional único, visto como uma estratégia para melhorar a qualidade do ensino básico. No anexo 
Metas e Estratégias, aparece então: "Fomentar a produção de material didático, o desenvolvimento de currículos e metodologias específicas, os instrumentos de avaliação [...]" (Brasil, 2014, 10.7).

A proposta de uma Base Nacional Comum Curricular (BNCC) só foi anunciada ao país no dia 16 de setembro de 2015. Elaborada por uma comissão de 116 pessoas - entre professores de História, pedagogos e docentes de universidades - "[...] apresentou os direitos e objetivos de aprendizagem e desenvolvimento que [deveriam] orientar a elaboração de currículos para as [...] etapas de escolarização" (Brasil, 2016, p. 24).

\section{Os componentes História e História Antiga na BNCC}

$\mathrm{O}$ intrigante foi que nessa apresentação da BNCC, o componente História ficou de fora, levando quase duas semanas para ser publicado. Domingues (2015) afirma que o atraso parece ter sido causado por discordâncias do ministro da educação e cultura, Renato Janine Ribeiro, às metas apresentadas pela equipe responsável pelo projeto.

Segundo Rede (2016), Ribeiro considerou o texto falho, cheio de lacunas e pouco didático. Inclusive, ao ser demitido do MEC, comentou publicamente que o projeto tinha:

[...] falhas de conteúdo; exclusão de horizontes essenciais da trajetória humana; ênfase exagerada em uma perspectiva endógena de História do Brasil [...]; abandono da cronologia, comprometendo o entendimento temporal dos processos sociais.

Outra crítica constante tem sido feita pelas Seções Regionais da Associação Nacional de História (ANPUH). Para essas, o documento propõe uma formulação genérica da disciplina História, com inúmeros objetivos que são repetitivos, pouco precisos e, às vezes, com redação confusa. Há, ainda, uma definição de conteúdos e conceitos, fatos e sujeitos históricos, sem que sejam explicitados os critérios de seleção e de organização que presidiram tais escolhas (ANPUH, 2016).

Após lermos tais críticas, surge um questionamento: como a História foi pensada, apresentada e organizada na BNCC? O projeto inicial privilegiou o rompimento com a perspectiva eurocêntrica, a partir de uma quebra da divisão 
quadripartite da História, isto é, Antiga, Medieval, Moderna e Contemporânea. O propósito era o de provocar um distanciamento em relação aos centros hegemônicos de poder, favorecendo conteúdos que tratassem de temas como diversidade, pluralidade e diferença cultural.

Apesar de a ideia mostrar-se enriquecedora e contribuir para a desconstrução de estereótipos, o que houve, de fato, foi uma preocupação exacerbada com o estudo da História do Brasil, das Américas e da África. Percebe-se, portanto, que a proposta original tinha uma lacuna inaceitável: a ausência de referências à História Antiga e à Medieval. De acordo com a ANPUH (2016),

Não há justificativa plausível para a omissão da História de povos da Antiguidade de diferentes partes do mundo que legaram um patrimônio material e imaterial reverenciado até os dias atuais. O mesmo deve ser dito em relação à História Medieval, tão imprescindível para se compreender modos de vida, ideias e valores que lhe são próprios e para refletir sobre processos de mudanças que ocorreram entre a Antiguidade e a Modernidade.

A eliminação da Antiguidade, em especial, trouxe de volta intensos debates que estavam adormecidos há algum tempo. Funari (2004, p. 2), por exemplo, já havia comentado que apesar de existirem dificuldades de se encontrar instrumentos didáticos para o ensino da História Antiga, não devemos esquecer que ela serve como instrumento de reflexão crítica, permitindo ao aluno repensar sobre as estruturas econômicas, sociais, políticas e culturais da atualidade. Dessa forma, o ensino da disciplina seria essencial para a formação de uma cidadania crítica e o seu abandono como objeto de reflexão ou seu conhecimento de segunda mão levaria ao aprofundamento do fosso entre a formação cultural das elites e das massas. Nesse sentido, para o autor,

o mundo clássico pode aparecer tanto como inspirador da luta pela liberdade e pela igualdade, como pode, mais comumente, servir para justificar o status quo patriarcal e opressivo. [...] A História da Antiguidade surge, então, como elo de ligação constante da realidade atual com suas origens ideológicas (Funari, 2004, p. 21-24) 
Franco Júnior (1987, p. 169) também já tinha se posicionado nesse debate. O historiador argumentou que uma possível justificativa para o "esquecimento" da História Antiga seria a pretensão de dar maior atenção aos períodos históricos diretamente ligados à compreensão da atual realidade brasileira. Todavia, afirmou que:

[...] não é possível analisar adequadamente uma construção histórica sem considerar suas fundações. De fato, o presente só pode ser compreendido a partir do estudo do passado, mas este deve ser visto no seu todo, pois levar em consideração apenas uma parcela dele, é arriscar-se a facilmente atingir conclusões frágeis (Franco Júnior, 1987, p. 169).

Guarinello (2003, p. 51-57) apresentou um argumento semelhante ao de Franco Júnior. O autor defendeu que apesar de a História Antiga ser um objeto muito distante pode ser entendida como uma possibilidade de entendermos o presente, embora de um modo mais complexo. Se os professores desenvolvessem uma consciência mais clara de como explicam o passado para seus alunos, talvez, esses compreendessem que a tradição que estudamos no Mundo Antigo é a nossa própria tradição. Em outras palavras, que o Brasil - e o mundo ocidental - possui heranças significativas da Tradição Clássica que influenciam diretamente em nosso cotidiano, como o direito, a língua portuguesa e a arquitetura. Por isso - mas não somente -, valeria a pena estudar História Antiga, contudo, sempre lembrando que ela precisa ser "[...] transformada para atender às necessidades do presente" (Guarinello, 2003, p. 57).

Sobre o estudo de aspectos da Tradição Clássica, Fortes e Miotti (2014, p. 161) defendem que os conteúdos vinculados à Arte, à História, à Arqueologia, à Filosofia e às Línguas devem ser abordados tendo como tema a cultura clássica, com a vantagem de, ao apresentar recortes dessa cultura na escola trazer à tona uma reflexão sobre os valores atuais da nossa cidadania, em contraste e em contato com aqueles dos gregos e romanos. Segundo os autores,

colocado em perspectiva, os valores do mundo clássico poderão ser motivo de discussão dos valores do nosso mundo, cujo conhecimento é franqueado também quando nos colocamos diante de nossas origens: indígenas, africanas, europeias, asiáticas, clássicas, 
múltiplas. O mundo antigo romano é apenas um entre os universos que entram na composição multicultural brasileira. De resto, a análise de textos e imagens da Antiguidade, em diferentes gêneros e datados de diferentes épocas, pode mobilizar saberes de áreas diversas (saberes históricos, literários, linguísticos, artísticos, entre outros), na formulação de um projeto transversal que contribua para o desenvolvimento cultural e cognitivo dos sujeitos da escola" (Fortes e Miotti, 2014, p. 161).

Depois de lermos os argumentos desses autores, tornou-se nítida a importância da História Antiga para a compreensão do nosso mundo, nosso presente. No entanto, se ela é tão importante por que ficou de fora do projeto inicial da BNCC? Acreditamos que existem três possíveis justificativas para essa questão. Em primeiro lugar, entendemos que a História Antiga, em geral, é percebida como uma disciplina muito distante temporalmente da contemporaneidade brasileira, o que dificulta e complexifica a realização de conexões. 3 Em segundo, cremos que, embora seja uma área em expansão, as pesquisas em Antiguidade Clássica ainda exigem do estudante determinados conhecimentos, a exemplo do inglês, do grego e do latim, para a leitura das fontes e das obras historiográficas. Em terceiro lugar, compreendemos que o fato de haver um distanciamento geográfico do Brasil em relação aos espaços do Mundo Clássico, como Grécia e Roma, inviabiliza não só os estudos, mas também os investimentos governamentais.

Apesar das dificuldades, as pesquisas em História Antiga têm se desenvolvido intensamente no Brasil. Docentes de Universidade como a USP, UNICAMP, UFMG, UFOP, UFES, UFG e UFPR vêm realizando orientações e publicando trabalhos que, cada vez mais, mostram o crescimento da área e a preocupação em investigar objetos que, além de estarem inseridos na atualidade brasileira, procuram analisá-la a partir das noções de permanências e rupturas. Dessa maneira, pensamos que a ausência da História Antiga na Base Nacional não possui fundamento. E para evidenciarmos isso, demonstraremos de que

\footnotetext{
3 Tal ideia foi discutida em 2015 numa mesa do XVIII Simpósio Nacional de História intitulada "Histórias 'não-brasileiras': a antiguidade e o medievo". A proposta dos membros presentes (Norberto Guarinello, Fábio Faversani e Maria Eurydice de Barros Ribeiro) era justamente tentar debater essa marginalização da História Antiga e comentar sobre os rumos das pesquisas na área. Disponível em: <http://www.snh2015.anpuh.org/conteudo/view?ID_CONTEUDO=1714>. Acesso em: 14 ago. 2016.
} 
forma as pesquisas na área foram e podem ser associadas às especificidades brasileiras.

\section{As pesquisas de História Antiga no Brasil}

A princípio, vejamos como os estudos foram integrados aos diversos contextos históricos do nosso país.

A disciplina de História Antiga foi inaugurada no Brasil por Eurípides Simões, na Universidade de São Paulo em 1940. Mas somente no final do século XX que começaria a expandir-se, primeiro nas universidades antigas e centrais, para, aos poucos, atingir as instituições novas e distantes (Carvalho e Funari, 2007, p. 14).

Em 1970, com a chegada da ditadura militar, a disciplina começou a ser vista, no meio universitário como controle ideológico, sendo identificada com a chamada direita política do país. Desse modo, as grandes universidades brasileiras adotaram currículos em que a História Antiga era estudada de maneira factual e positivista. O estudante aprendia “[...] os feitos de personagens considerados grandes [...]” e eles eram ensinados sob a forma de “[...] uma linha contínua com acontecimentos com causa e efeito, sem a análise fundamental dos processos históricos [...]” (Silva, 2010, p. 147).

Com a abertura política da década de 1980, há um aumento das produções historiográficas. As abordagens marxistas ganham força e os antiquistas passam a utilizar as reflexões de Moses Finley, historiador inglês da Antiguidade de vertente weberiana, para a escrita de seus trabalhos. Nos anos 90, por sua vez, outros temas são pesquisados. Com o advento da História Cultural, expandindo-se em nível nacional, novos métodos e objetos apareceram, o que provocou uma multiplicação de dissertações e teses influenciadas pelos conceitos de representação e identidade.

Nos dias atuais, as pesquisas em História Antiga no Brasil têm recebido reconhecimento nacional e internacional. Como prova disso temos: os Simpósios Temáticos da área nos encontros regionais e nacionais da ANPUH; congressos de História Antiga em várias universidades do Brasil; publicações de textos e livros de renomados pesquisadores; e um aumento das cadeiras dedicadas a professores dessa modalidade nas universidades (Silva, 2010, p. 146). Logo, cada vez mais atentas às suas inserções nas discussões 
internacionais, as pesquisas não hesitam “[...] em mostrar como as especificidades brasileiras podem ser usadas, de maneira produtiva e fertilizadora, para contribuir com os debates nos ambientes hegemônicos" (Carvalho e Funari, 2007, p. 16).

Após esse breve panorama, vejamos agora como as pesquisas em História Antiga podem ser integradas às especificidades brasileiras.

\section{O imperador Nero e o Brasil contemporâneo}

Desde meados de 2013, um assunto que inegavelmente tem marcado o nosso cotidiano é a política do Governo Dilma. Incontáveis notícias circularam nos mais diversos meios de comunicação, como jornais e redes sociais, com esse conteúdo em pauta. A opinião pública havia sido condicionada a associar toda e qualquer discussão - mesmo aquelas ligadas a temas esportivos e/ou pessoais à legitimidade de um governo que passava a ser contestado por seus opositores políticos.

Basicamente, o tópico debatido no âmbito das notícias e dos rumores políticos era o seguinte: um governo acusado de corrupção estaria apto para continuar conduzindo o país? A fim de responder esse questionamento, as pesquisas de opinião e a argumentação diária das pessoas passaram a selecionar informações que atacavam a figura da Presidenta Dilma Rousseff e o seu programa de governo.

Como sabemos, nos últimos quatorze anos, o Brasil foi administrado por dois presidentes eleitos democraticamente - Luiz Inácio Lula da Silva e Dilma - e que assumiram como bandeira a defesa de políticas de cunho social, a qual nunca foi bem aceita pelos grupos mais oligárquicos. Em 2014, quando esses últimos tiveram uma derrota nas urnas, ficou claro que os projetos sociais do Partido dos Trabalhadores (PT) não seriam mais aceitos.

A partir daí os opositores iniciaram uma política de difamação da imagem da Presidenta eleita, no intuito de justificar um já pensado processo de impeachment. O descrédito aparentemente surtiu resultado, uma vez que houve manifestações populares de hostilidade nos estádios da Copa do Mundo e passeatas organizadas por grupos políticos/civis na tentativa de ilegitimar o governo. Tal processo prolongou-se pelos primeiros anos do mandato da 
Presidenta, contando com o apoio incondicional dos veículos de imprensa. O resultado final: o impeachment de Dilma, em 2016.

É intrigante pensar que esse afastamento se deu muito mais pela opinião pública e pela construção de uma imagem de uma governante incapaz do que por motivos realmente jurídicos e constitucionais. Aliás, a Presidenta não tinha sobre si nenhuma acusação formal. Por isso, acreditamos que algumas indagações merecem ser levantadas aqui: o que faz um bom governo? E o que faz um mau governo (que merece ser derrubado)? Existe um bom governante e um mau governante?

Essas questões nos introduzem ao debate de como os critérios para a avaliação dos governantes e de seus governos devem ser analisados historicamente. Para tanto, vamos propor uma investigação sobre o quão útil a realidade política brasileira pode ser para avaliarmos, por exemplo, os imperadores romanos.

Para os antiquistas do século XIX, o Império Romano deveria ser estudado com ênfase nos grandes homens e em seus feitos políticos e militares. Inúmeras biografias e trabalhos historiográficos, então, foram escritos com o propósito de rememorar o governo desses personagens. A realização de tal resgate, contudo, era feita sob a ótica dos maus exemplos dos maus governantes, os quais eram destacados justamente para não serem imitados. Assim, um mau governo passou a ser o resultado de um mau governante. E mau por ser visto sob a ótica de ações ruins, fruto de seus defeitos de cunho moral, militar, educacional e até mesmo genético/familiar. Inclusive, um dos imperadores lidos e representados dessa maneira foi Nero.

São muito conhecidas as narrativas do mundo greco-romano que consideraram o Principado de Nero César Augusto (54-68 d.C.) como a encarnação do exagero, da devassidão e da crueldade.4 Célebres são as passagens que nos informam como Nero assassinou sua mãe Agripina, chutou sua esposa grávida até a morte, castrou um liberto e casou-se com ele, estuprou uma Vestal e mandou queimar a cidade de Roma (Champlin, 2003, p. 36).

\footnotetext{
4 As narrativas da crueldade e da corrupção de Nero romperam as fronteiras da Antiguidade, podendo ser lidas na literatura moderna: foi esse imperador que teria servido de inspiração para a escrita do matricídio na obra Hamlet, de Shakespeare, e do fratricídio em Britannicus, de Racine (Griffin, 2001, p. 16).
} 
Informações que possuem respaldo de um reconhecido e central conjunto de fontes produzido na Idade Antiga: os Anais, de Tácito; A Vida dos Doze Césares, de Suetônio, e a História Romana, de Dião Cássio - obras compostas entre a primeira metade do século II e a primeira metade do século III, isto é, posteriores aos eventos que narram.

Ao lermos tais fontes, não é difícil identificar a origem das críticas a respeito do princeps: "Nero ainda continuou por muitos anos a governar, e a ser pelos seus crimes o flagelo do mundo" (Tácito Anais 14.12); "Prostituía-se de forma que não havia um só dos seus membros que não estivesse maculado e [...] não pôs nenhum limite às suas despesas e profusões" (Suetônio Nero 29-30); "Ele se envolvia em muitos atos licenciosos tanto em casa quanto na cidade [...]. Em consequência, golpes e violências frequentes ocorreram, e o mal se espalhou [...]" (Dião Cássio Historia Romana 61.8.1).

Parece que as críticas, então, se tornaram um lugar comum. Sustentadas pelas fontes, atravessaram várias épocas, dando centralidade a uma memória lúgubre de Nero e de seu Principado, a uma espécie de verdade, vulgata. ${ }^{5}$ Mas não haveria aqui senão uma verdade parcial? Talvez haja várias. Em outros termos, os Anais, A vida dos Doze Césares e a História Romana não são as únicas fontes a tratarem do Principado neroniano. Não existiriam outras tão importantes quanto essas e muito mais próximas temporalmente do objeto que analisam? Exemplos seriam: Sobre a Clemência, escrita por Sêneca; Bucólicas, de Calpúrnio Sículo, e Farsália, de Lucano, compostas na segunda metade do século I, por contemporâneos ao governo do soberano.

Nesse corpus documental, observamos elogios à bondade do imperador - "Isso teria sido difícil se a bondade não fosse natural em ti, mas encenada de vez em quando" (Sêneca Sobre a Clemência Proêmio 1.6) -, enaltecimentos à era de paz instaurada no Império - "[...] aquele que o nosso mundo governa com a sua divindade propícia e a paz perpétua mantém, com vigor juvenil" (Calpúrnio Sículo Bucólicas 4.84-86) -, e louvores à sua divindade - "Mas para mim já és um deus; e se, como um vate, te aceito no meu peito, não desejo invocar o deus que revela os segredos de Cirra, nem fazer Baco retornar de Nisa:

\footnotetext{
5 Destacamos a obra do escritor polonês Sienkiewicck (1895), intitulada Quo Vadis, que foi adaptada para o cinema em 1951, pelo diretor Leroy. O filme e a obra em ponto trabalham em um universo bastante imaginativo, representando Nero como louco, sanguinário e depravado sexualmente.
} 
tu és o bastante para dar vida a um poema romano" (Lucano Bellum Civile 1.6366).

A despeito das fontes antigas, Winterling (2012, p. 6) comenta que, em geral, são escritas na posterioridade da vida dos governantes, apresentando sempre parcialidade política. Não podem ser vistas, portanto, como fontes "isentas" e sim como produções que demonstram interesses específicos da elite aristocrática que, muitas vezes, tinha o interesse direto em promover um novo imperador em cima do detrimento moral e político do anterior.

Ainda para o historiador, a maneira pela qual

[...] esses imperadores são retratados nas fontes antigas não apenas é claramente pouco confiável, mas, em grande medida, caracterizada por declarações que são evidentemente incorretas.

Dito de outra forma, os critérios de julgamento empregados para o governo e o caráter dos imperadores devem sempre ser historicizados (Winterling, 2012, p. 5).

Aqui atingimos o ponto desejado de nossa discussão: o quanto a política brasileira é útil para a proposição de abordagens sobre o mundo antigo e viceversa. Se levarmos em consideração o que foi explicitado sobre o governo Dilma e o Principado neroniano, perceberemos que não há e nunca haverá um consenso universal sobre os governantes.

Por exemplo, ao falarmos de novo acerca do reinado de Nero destacamos que o fim de seu Principado, isto é, a sua queda, não ocorreu por ele ser consensualmente mau. Ao contrário, com base nas Histórias (1.89) de Tácito, esclarecemos que sua queda se deu muito mais "por notícias e rumores", ou seja, por uma política de difamação do imperador pelos seus adversários, do que por um governo realmente ruim. Isso fica mais evidente ao atentarmos para a seguinte passagem de Suetônio:

Morreu no trigésimo segundo ano de sua vida [...] e tal foi a alegria pública, que a plebe se regozijou ostentando o gorro da liberdade por toda a cidade. No entanto, por um longo período de tempo, houve quem decorasse seu túmulo com flores da primavera e do verão, e nos rostra colocaram [...] seus editos, como se ele ainda estivesse vivo e retornando para derrotar seus inimigos maus. Também, Vologeso, rei dos Partos [...] 
implorou que deveria prestar honra à memória de Nero. Na verdade, vinte anos depois, quando eu era jovem, uma pessoa de origem incerta que dizia ser Nero apareceu, e este nome era tão favorável no meio dos partas que ele foi vigorosamente acolhido por eles [...] (Suet. Ner. 57).

Como se vê, as manifestações em relação à morte do princeps foram ambíguas: algumas pessoas ficaram felizes e outras tristes. Aliás, o próprio apoio a Nero e o culto a sua pessoa continuaram por muitos anos depois do seu falecimento. Fato que fortalece outra uma vez a ideia de que ao lidarmos com governantes e governos polêmicos, os critérios de julgamento nunca são consensuais. Na verdade, o que existe é uma disputa política pela opinião pública para justificar a queda de um governante considerado ruim; ou a construção de um golpe de Estado contra um governo dito ilegítimo.

Destarte, Nero não caiu necessariamente por ser "louco", mas pela edificação, consolidação e divulgação de uma imagem negativa a seu respeito por parte dos grupos aristocráticos. O mesmo pode ser dito de nossa Presidenta. Ao longo de todo o processo de impeachment, o que ficou nítido foi que Dilma era incapaz de gerir o Brasil não por não possuir capacidades administrativas ou políticas, mas por ser arrogante, histérica e "louca". 6 É o que nos mostra a revista Istoé:

6 "From our history books we all learned Nero fiddled while Rome was burned. Ain't that just like a woman? Ain't that just like a woman? Ain't that just like a woman? They'll do it every time". Ain't That Just Like a Woman (They'll Do It Every Time)”. Jordan, L. Ain't That Just Like a Woman (They'll Do It Every Time). In: Let the good times roll: The Anthology. USA: Decca, 1946. 


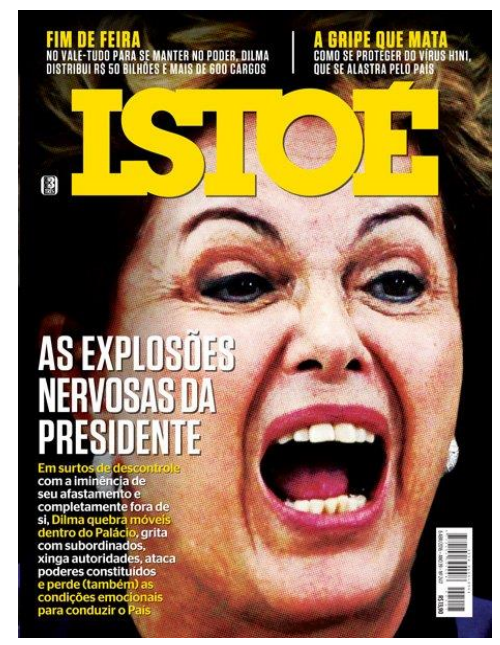

Figura 1 - Capa da Revista Istoé: As explosões nervosas da Presidenta (Fonte: http://www.cartacapital.com.br/blogs/midiatico/quando-a-misoginia-pauta-ascriticas-ao-governo-dilma)

Logo, o mandato de Dilma também acabou sendo depreciado devido a um recorte seletivo das informações por parte da imprensa e de seus opositores.7 Uma seleção feita com base em uma forte carga de conjunturas e interesses específicos. De certo, até mesmo as políticas sociais do PT, que a nosso ver deveriam ser encaradas como boas táticas de governo, passaram a servir como sintomas de uma má administração.

\section{Considerações finais}

$\mathrm{O}$ anacronismo feito até aqui entre a política brasileira e a romana nos possibilita afirmar que a proposta da BNCC deve ser reconsiderada - como já o foi. A conexão construída nesse artigo vai ao encontro de tudo o que os autores citados por nós argumentaram, ou seja, de que “[...] os valores do mundo clássico poderão ser motivo de discussão dos valores do nosso mundo [...]" (Fortes e Miotti, 2014, p. 161) e que a História Antiga pode servir como "[...] instrumento de reflexão crítica, permitindo ao aluno repensar sobre as

\footnotetext{
7 A essa altura, é oportuna uma reflexão de Thornton (1973, p. 570), que nos lembra: "onde os fatos por si mesmos estão obscurecidos e [...] seus intérpretes são tendenciosos, a reputação talvez não seja merecida. Aonde a disponibilidade da veracidade dos fatos é limitada, a reinterpretação de algumas peças de evidência pode levar a uma maior revisão da reputação histórica”.
} 
estruturas econômicas, sociais, políticas e culturais da atualidade" (Funari, 2004, p. 2).

O estudo do passado romano, sem dúvida, nos auxilia a refletir sobre problemas importantes que o nosso país vem passando. Fato que inviabiliza, outra vez, o argumento de que a História Antiga é muito distante temporalmente da contemporaneidade brasileira. Ora, não é porque uma disciplina possui acontecimentos considerados longínquos que ela necessariamente precise ser abandonada. Quer dizer então que não somos capazes de relacionar um passado remoto com o presente? Que estamos fadados a trabalhar somente com o atual?

Para Agamben (2009, p. 58) nada seria mais temerário. O autor defende que manter os olhos fixos em uma única época não autoriza aos sujeitos enxergarem e compreenderem suas realidades. O ideal seria que o indivíduo não coincidisse perfeitamente com o seu tempo e nem se adequasse às suas pretensões, pois somente através de um deslocamento e de um anacronismo que o sujeito tornar-se-ia capaz, mais do que outros, de perceber e apreender o seu tempo.

Chamamos a atenção, portanto, para a conjectura de que somos contemporâneos de todos os seres humanos. Como dizia Kandinsky (1991, p. 130), a matéria morta é - e carece ser vista como - espírito vivo. O que nos leva a concordar com Burlamaqui (1935, p. 194) quando afirma que a

abstração do tempo é necessária pelo fato da vida ser dinâmica, isto é, existir o movimento e a evolução. Um homem que se estudar em um momento, não se conhecerá. O presente de um homem é, porém, um resultado do seu passado e do de seus antepassados. (Burlamaqui, 1935, p. 194).

Os objetos da História, se investigados "deslocados de seu tempo", fora da cronologia linear ou a partir de tempos impuros e justapostos acabam ganhando dimensão e profundidade. É justamente essa ligação entre múltiplas temporalidades que nos facultou apreender o afastamento da Presidenta e notar que há a possibilidade de um acontecimento ocorrer em diversos contextos históricos com a mesma configuração (Flores, 2014, p. 437). 
Assim sendo, o tema do anacronismo torna-se promissor para ponderarmos uma nova maneira de lidar com o tempo e com os fatos na História. Uma maneira que descubra direções, saltos ou conexões temporais que deem sentido ao "fazer" histórico. Isso significa que o passado, o presente e o futuro não precisam ser forçosamente concebidos de modo sequencial, mas sim interconectados e com espaços interativos. Em outras palavras, que é possível analisar o passado através de uma concepção de tempo não-linear.

Nesse ínterim, Lorenz (2014, p. 45) afirma que tal concepção propicia a nós pensarmos sobre uma simultaneidade temporal, uma pluralização que pressupõe a existência do passado no presente. Inclusive, o autor sustenta a noção de uma História "quente", isto é, aquela que se utiliza de um passado que não se "esfria" por si mesmo e que permanece presente.

Essas são questões mais que importantes, pois acreditamos que uma perspectiva não-linear autoriza-nos acessar aspectos da nossa realidade política que não seriam passíveis de interpretação por intermédio somente da própria contemporaneidade. Através de uma multidimensionalidade, os historiadores podem captar com maior nitidez, por exemplo, os interesses e os modos de pensar de determinados grupos políticos que, de outra forma, escapariam à percepção.

Somos convidados, por fim, a assimilar que o passado não está presente, mas que nenhum presente é inteiramente separado ou não influenciado pelo passado (Bevernage e Lorenz, 2013, p. 28). Ao combinarmos essa ideia com a frase de Faulkner (1951, p. 92) - "o passado nunca está morto" - estaremos mais aptos para compreender que a política de uma época ou de um país dificilmente permitirá consensos. Seja em Roma ou no Brasil, a política é sempre feita com base na edificação arbitrária da imagem dos governantes, sendo os detentores dos meios de comunicação e os líderes da opinião pública os maiores construtores dos julgamentos de um governo. 


\section{Referências Bibliográficas}

Fontes Primárias

Calpúrnio Sículo. Bucolics. Trans. by J. Wight Duff and Arnold M. Duff. London: Loeb Classical Library, 1934.

. Bucólicas. Trad. de João Beato. Lisboa: Verbo, 1996.

Cassius Dio. The Roman history. Trans. by Earnest Cary. London: The Loeb Classical Library, 1927. v. 8.

Lucano. Farsália: cantos de I a V. Trad. de Brunno V. G. Vieira. Campinas: Ed. da Unicamp, 2011.

Sêneca. Tratado sobre a clemência. Trad. de Ingeborg Braren. Petrópolis: Vozes, 2013.

Suetonius. Lives of the Caesars. London: Loeb Classical Library, 1997. v. 2.

The lives of the twelve Caesars. Trans. by Catharine Edwards. Oxford: Oxford University Press, 2000.

Tácito, C. Anais. Trad. J. L. F. de Carvalho. São Paulo: W. M. Jackson Inc., 1952. v. XXV.

Classical Library, 1992

Histories: books 1-3. Trans. by Clifford H. Moore. London: Loeb

The Annals. Trans. by A. J. Woodman. Indianapolis: Hackett Publishing Company, 2004.

\section{Bibliografia Crítica}

Agamben, Giorgio. O que é o contemporâneo. Trad. Vinícios N. Honesko. Chapecó: Argos, 2009.

ANPUH. Manifestação pública da ANPUH sobre a Base Nacional Comum Curricular. Disponível em: < http://site.anpuh.org/index.php/2015-01-20-oo01-55/noticias2/noticias-destaque/item/3352-manifestacao-publica-da-anpuhsobre-a-base-nacional-comum-curricular>. Acesso em: 13 ago. 2016.

Bevernage, B.; Lorenz, C. Breaking up time - Negotiating the borders between present, past and future: An introduction. In: BEVERNAGE, B.; LORENZ, C. (orgs.). Breaking up time: negotiating the borders between present, past and futures. Göttingen: Vandenhoeck and Ruprecht, 2013. p. 7-36.

Brasil. Base Nacional Comum Curricular (BNCC). Brasília: MEC, 2016. 1988. . Constituição da República Federativa do Brasil. Brasília: Senado, dez. de 1996.

Lei de Diretrizes e Bases da Educação Nacional. Lei n. 9394, 20 de - Parâmetros Curriculares Nacionais (PCNs). Brasília: MEC/SEF, 1997-1998.

. Plano Nacional de Educação (PNE). Brasília: INEP, 2014. 
Burlamaqui, Jorge. Abstração do tempo e do espaço. A Ordem, Rio de Janeiro, p. 193-195, 1935.

Carvalho, M. M. de; Funari, P. P. Os avanços da História Antiga no Brasil: algumas ponderações. História, São Paulo, v. 26, n. 1, p. 14-19, 2007.

Champlin, E. Nero. Massachusetts: Harvard University Press, 2003.

Domingues, J. E. Base Curricular Comum: afinal, o que ensinar de História? Disponível em: <http://www.ensinarhistoriajoelza.com.br/base-curricularcomum-o-que-ensinar-de-historia/>. Acesso em: 13 ago. 2016.

Faulkner, W. Requiem for a Nun. New York: Signet, 1951.

Flores, M. B. R. Elogio do anacronismo: para os andróginos de Ismael Nery. Topoi, Rio de Janeiro, v. 15, n. 29, 2014.

Fortes, F. S.; Miotti, C. M. Cultura clássica e ensino: uma reflexão sobre a presença dos gregos e latinos na escola. Organon, Porto Alegre, v. 29, n. 56, p. 153-173, 2014.

Franco Junior, H. Os estudos medievalísticos no Brasil. Projeto História, PUCSP, v.7, p. 169-179, 1987.

Funari, P. P. A importância de uma abordagem crítica da História Antiga nos livros escolares. Revista História Hoje, São Paulo, n. 4, 2004.

Griffin, M. T. Nero: the end of a dynasty. London: B. T. Batsford, 2001.

Guarinello, N. L. Uma morfologia da História: As formas da História Antiga. Politeia, Vitória da Conquista, v. 3, n. 1, p. 41-61, 2003.

Kandinsky, Wassily. Olhar sobre o passado. Trad. Antônio de Pádua Danesi. São Paulo: Martins Fontes, 1991.

Koselleck, R. Estratos do tempo: estudos sobre História. Rio de Janeiro: Editora da PUC-Rio, 2014.

Lorenz, C. Blurred Lines: History, Memory and the Experience of Time. HCM, v. 2, n. 1, p. 43-63, 2014.

Rede, M. $O$ assassinato da História. Disponível em: < http://www1.folha.uol.com.br/paywall/adblock.shtml?origin=after\&url=http:// m.folha.uol.com.br/opiniao/2016/02/1744204-o-assassinato-dahistoria.shtml>. Acesso em: 13 ago. 2016.

Silva, S. C. Aspectos do ensino de História Antiga no Brasil: algumas observações. Alétheia, v. 1, p. 145-155, 2010.

Thornton, M. K. The enigma of Nero's quinquennium. Historia, Cambridge, v. 22, n. 4, p. 570-582, 1973.

Winterling, A. Loucura Imperial na Roma Antiga. História, São Paulo, v. 31, n. 1, p. 4-26, 2012. 